\section{Canal Preparation and Filling Techniques do not Influence the Fracture Resistance of Extensively Damaged Teeth}

Manuela Favarin Santini ${ }^{1}$, Marilia Pivetta Rippe ${ }^{2}$, Gisele Jung Franciscatto ${ }^{3}$, Ricardo Abreu da Rosa', Luiz Felipe Valandro ${ }^{4}$, Marcus Vinícius Reis Só', Carlos Alexandre Souza Bier ${ }^{3}$
'Department of Conservative Dentistry, UFRGS - Federal University of Rio Grande do Sul, Porto Alegre, RS, Brazil ${ }^{2}$ Department of Dental Materials and Prosthodontics, School of Dentistry of São José dos Campos, UNESP - Univ Estadual Paulista, São José dos Campos, SP, Brazil ${ }^{3}$ Department of Stomatology, UFSM - Federal University of Santa Maria, Santa Maria, RS, Brazil ${ }^{4}$ Department of Restorative Dentistry, UFSM - Federal University of Santa Maria, Santa Maria, RS, Brazil

Correspondence: Prof. Dr. Luiz Felipe Valandro, Rua Floriano Peixoto, 1184, 97015-372, Santa Maria, RS, Brazil. Tel: +55-55-3220-9276. e-mail: Ifvalandro@hotmail.com
The purpose of this study was to assess the fracture resistance of extensively damaged teeth after two root canal preparation techniques (hand and rotary files) and after two filling techniques (active and passive compaction). Sixty-eight maxillary canines roots with an apical diameter equal to that of a \#25 K-file were embedded in acrylic resin and the periodontal ligament was simulated by using a polyether impression material. The roots were randomly distributed into four groups $(n=17)$ : hand preparation and active compaction ( $\mathrm{HA})$, hand preparation and passive compaction (HP), rotary preparation and active compaction (RA), and rotary preparation and passive compaction (RP). All roots were restored with glass fiber post and metallic crown. The specimens were mechanically cycled $\left(500,000\right.$ cycles, $\left.45^{\circ}, 37^{\circ} \mathrm{C}, 133 \mathrm{~N}, 2 \mathrm{~Hz}\right)$ and then subjected to a fracture resistance test. A single blinded examiner analyzed the external root surface and classified the failure pattern as favorable or unfavorable. The fracture resistance values ranged between 621.15 $\mathrm{N}(\mathrm{HP})$ and $785.71 \mathrm{~N}(\mathrm{HA})$. However, the Kruskal-Wallis test did not reveal differences in the fracture resistance values among the four groups ( $p=0.247)$. Under the tested conditions, root canal preparation and filling techniques had no influence on the fracture resistance of extensively damaged teeth restored with fiber post and metallic crown.
Key Words: root canal preparation techniques, root canal filling techniques, vertical root fracture, glass fiber post.

\section{Introduction}

Vertical root fracture (VRF) is one of the major causes of failure in endodontically treated teeth (1). A VRF is defined as a longitudinal fracture that usually begins on the internal wall and extends outward to the root surface (1). The diagnosis of a VRF is difficult (2) and invasive interventions, such as tooth extraction, are often required for its treatment (3). When it is possible to maintain the tooth, rhizectomy can be performed (multirooted tooth), but the prognosis of this therapy is poor (4). Therefore, it is important to prevent VRFs by determining and understanding their etiology.

According to the literature, the prevalence of a VRF in extracted endodontically treated teeth is approximately $11 \%(5)$. The main causes of VRFs are excessive enlargement of root canal, application of excessive pressure during lateral compaction of gutta-percha and inappropriate post selection and post cementation technique (6). Other factors like internal bleaching (7), type of post (8), amount of the removed dentin (6) and root canal preparation and filling techniques (9) may affect the fracture resistance of endodontically treated teeth.

The appearance of dentin defects may vary according to the type of instrument used for root canal preparation (hand files or rotary systems). Certain morphological features (i.e., design of the cutting blades, cross section, and body taper) may generate different degrees of irregularity in the root canal, thereby changing the pattern of stress distribution (10). However, there is no consensus regarding the most suitable technique for root canal preparation that causes lesser damage to the tooth structure.

The stress generated by the spreader during root canal filling may also induce a VRF. The stress occurs due to the wedge effect on the root canal when the load is applied to the spreader (11). On the other hand, previous reports have demonstrated that lateral compaction can induce dentin defects; however, this condensation is not a direct cause of a VRF $(12,13)$. According to Fuss et al. (5), the survival rate of endodontically treated teeth depends more of the coronary reconstruction than endodontic treatment. Generally, endodontically treated teeth have minimal coronal structure remaining, and therefore, intraradicular posts are needed for retaining the restorative material. Previous reports evaluated the effect of root dentin thickness, type and length of intraradicular posts, ferrule presence, and cement used for post cementation on the fracture resistance of endodontically treated teeth $(14,15)$. However, no study has investigated the influence of different canal preparations and fillings techniques on the fracture resistance of teeth that require a prosthetic 
approach. Therefore, the purpose of this study was to assess the fracture resistance of widely damaged teeth restored with fiber post and metallic crown after two root canal preparation techniques (hand and rotary files) and after two filling techniques (active and passive compaction). The null hypothesis was that the canal preparation and filling techniques do not influence the fracture resistance of extensively damage teeth restored with fiber posts and metallic crown.

\section{Material and Methods}

This study was submitted for ethical review and was approved by the Ethical Committee of the Federal University of Santa Maria (23081.020151/2010-15). The sample size calculation was based on the difference between means obtained from a pilot study and was performed at the 95\% level of confidence and $80 \%$ statistical power. The test indicated that it would be necessary 17 teeth per group. Thus, 68 maxillary canines were selected. The external root surface was examined with a loupe at $4 \times$ magnification (EyeMag Pro S; Carl Zeiss do Brasil Ltda., São Paulo, SP, Brazil), and teeth with cracks or fracture lines were excluded. In addition, teeth with extensive caries, calcifications, mesiodistal flattening and previous endodontic treatment were excluded. To evaluate these parameters, radiographs of the buccolingual and mesiodistal aspects were taken. Teeth with the above-mentioned inclusion criteria were cleaned and stored in distilled water at $4{ }^{\circ} \mathrm{C}$.

All of the roots were sectioned transversally at $15 \mathrm{~mm}$ from the apex, and the canal patency was established with a \#15 K-file (MANI, Inc.; Nakaakutsu, Takanezawa-Machi, Japan). Only roots with an apical diameter equal to that of a \#25 K-file were included in this study in order to standardize the root dimensions.

\section{Periodontal Ligament Simulation and Root Embedding}

The roots were embedded in plastic cylinders $(15 \mathrm{~mm}$ in height and $25 \mathrm{~mm}$ in diameter) for simulation of the periodontal ligament. Each root was immersed in melted wax (Newwax, Technew, Rio de Janeiro, RJ, Brazil) up to $3 \mathrm{~mm}$ from the cervical edge of the root to simulate the biological space. Then, a $0.2-$ to $0.3-\mathrm{mm}$ thick wax layer was obtained after cooling. Thereafter, the roots were embedded in a polyvinyl chloride (PVC) cylinder filled with a chemically polymerized acrylic resin (Dencrilay; Dencril, São Paulo, SP, Brazil) with the aid of a parallelometer. The use of a parallelometer guarantee that the long axes of the root and cylinder would be parallel to each other and perpendicular to the ground. Next, the acrylic resin was prepared and poured inside the cylinder and the root was immersed up to the cementoenamel junction. After resin polymerization, the wax was removed from the root surface and the resin cylinder 'sockets' by using gauzes. The resin cylinders were filled with a polyether impression material (Impregum ${ }^{\mathrm{TM}}$ Soft; $3 \mathrm{M}$ ESPE, St. Paul, MN, USA) by using a molding syringe. The teeth were re-inserted into their respective cylinder 'sockets', and any excess impression material was removed with a \#12 scalpel blade.

\section{Cleaning and Shaping Procedures}

The roots were then randomly divided into two main groups ( $n=34)$ according to the root canal preparation.

Hand preparation $(\mathrm{H})$ : Canal preparation was performed with K-files (MANI) according to a crown-down technique up to the working length (WL). Once the WL was reached, the root canal was prepared sequentially with $25.02,30.02$, 35.02 and $40.02 \mathrm{~K}$-files. Next, the step-back technique was performed in $1 \mathrm{~mm}$ increments up to a \#60 K-files in order to promote a 0.05 taper preparation.

Rotary preparation $(\mathrm{R})$ : The root canals were prepared with nickel-titanium (NiTi) rotary files (NRT NiTi, MANI). The canal preparation was performed with 0.06 and 0.04 taper instruments (\#40 to \#25) alternately by using the crown-down technique until the WL was reached. Then, the canal was prepared to the full WL with a \#40.06 instrument, promoting a 0.06 taper preparation. The instruments were rotated at $300 \mathrm{rpm}$ with a torque setting of approximately $1.5 \mathrm{~N} / \mathrm{cm}$ (Endo Pro Torque, Driller, Jaguaré, SP, Brazil).

In all groups, irrigation was carried out with $2 \mathrm{~mL}$ of $2.5 \%$ sodium hypochlorite $(\mathrm{NaOCl})$ after each instrument change by using a disposable syringe and Endo Eze tips (Ultradent Products Inc., Indaiatuba, SP, Brazil), followed by irrigation with $2 \mathrm{~mL}$ of $17 \%$ ethylenediaminetetraacetic acid (EDTA) for $3 \mathrm{~min}$. A final rinse was performed with 5 $\mathrm{mL}$ of distilled water, and the canals were dried with paper points (ROEKO, Coltène/ Whaledent, NY, USA). After canal preparation, the cervical portion of each root was analyzed with a stereomicroscope at $15 \times$ magnification (Stereo Discovery V20, Carl Zeiss, Jena, Germany).

\section{Root Canal Filling}

The two main groups (hand and rotary preparation) were subdivided according to the filling technique $(n=17)$ :

Active compaction (A): \#40 gutta-percha master cones (ROEKO) were used in combination with an epoxy resin-based sealer (AH Plus, Dentsply Maillefer, Ballaigues, Switzerland). The lateral compaction was performed with a size $C$ spreader ( $\mathrm{D}_{0}$ diameter $0.3 \mathrm{~mm}, 0.04$ taper) (MANI) and size 25 gutta-percha accessory cones (ROEKO). Accessory cones were inserted into the root canal and compacted until the spreader could not penetrate more than $5 \mathrm{~mm}$ inside the root canal. The compaction load was controlled by a digital scale and was kept at a maximum of $3 \mathrm{~kg}$ (Kern 440-53; Kern \&t Sohn GmbH, Ziegelei, Balingen-Frommern, 
Germany).

Passive compaction (P): The accessory gutta-percha cones were passively inserted without using a spreader to the depth at which resistance was reached (13). The excess of gutta-percha was removed with a flame-heated plugger, and the canal opening was sealed with a temporary restorative material (Coltosol, Coltène/Whaledent). Finally, the roots were stored for $24 \mathrm{~h}$ at $37^{\circ} \mathrm{C}$ and $100 \%$ humidity to allow the sealers to set.

\section{Post Cementation Procedures}

A size 3 Largo drill was used for partial filling removal (MANI) to a depth of $10 \mathrm{~mm}$. Thereafter, the post space was prepared with a size 2 drill $\left(D_{0}\right.$ diameter $0.9 \mathrm{~mm}, D_{10}$ diameter $1.4 \mathrm{~mm}$ ) from the White Post DC kit (White Post DC, FGM, Joinvile, SC, Brazil). Next, the post space was flushed with $2 \mathrm{~mL}$ of $2.5 \% \mathrm{NaOCl}$ and dried with paper points. After the post space preparation, the cervical portion of each root was analyzed with a stereomicroscope at $15 x$ magnification (Stereo Discovery V20).

Before cementation, the fiber posts were cleaned with isopropyl alcohol and silanized (Prosil, FGM). The selfadhesive resin cement (RelyX U100, 3M ESPE) was mixed and inserted into the canal with a lentulo drill (MANI), and the fiber post was immediately placed into the root canal. Finally, the cement was light-cured (Radii-cal; SDI, Bayswater, Victoria, Australia) for $40 \mathrm{~s}$.

The core was built up with composite resin (Opallis, FGM) with standardized plastic matrices. Initially, the cervical dentin was etched with $37 \%$ phosphoric acid (37 Condac, FGM) for $15 \mathrm{~s}$ and rinsed with water spray for $30 \mathrm{~s}$. After drying, a one-step adhesive (Ambar, FGM) was applied onto the dentin surface with a microbrush. The composite resin was applied around the post and light-cured to avoid failures at the post/composite resin interface. Then, the matrix was filled with composite resin and positioned on the post. The buccal, lingual, mesial and distal surfaces were light-cured for $20 \mathrm{~s}$ each. Finally, the core of each specimen was reprepared with the \#4137 diamond bur (KG Sorensen, Barueri, SP, Brazil). Full nickel-chromium crowns were fabricated with dimensions simulating those of the maxillary canines and luted with a self-adhesive resin cement (RelyX U100). The specimens were stored in distilled water at $37^{\circ} \mathrm{C}$ for $24 \mathrm{~h}$.

\section{Mechanical Cycling}

The specimens were placed in metallic devices and submitted to mechanical cycling for 500,000 cycles $(133 \mathrm{~N}$, $45^{\circ}, 2 \mathrm{~Hz}, 37^{\circ} \mathrm{C}$ ) on the palatal aspect in a cycling machine (ER 11000; ERIOS, São Paulo, SP, Brazil). During mechanical cycling, the specimens were immersed in distilled water at $37{ }^{\circ} \mathrm{C}$.

\section{Fracture Resistance Test}

Immediately after mechanical cycling, the specimens were submitted to the static fracture resistance test by using an universal testing machine (DL-1000, Emic, São José dos Pinhais, PR, Brazil). The compressive load was applied on the palatal aspect of the crowns with a round steel device at a crosshead speed of $1 \mathrm{~mm} / \mathrm{min}$. The load necessary to fracture each specimen was recorded.

The failure patterns were analyzed and classified as favorable (displacement of the crown and/or post; radicular fracture up to or above the simulated bone level, i.e., the edge of the acrylic resin block) or unfavorable (radicular fracture below the simulated bone level). A single blinded examiner previously calibrated, analyzed the external root surface. The categorization was performed by using transillumination and a loupe at $4 \times$ magnification (EyeMag Pro S).

The external surface of the roots was not assessed after the each preparation and filling steps because the purpose of the study was to evaluate the association of these procedures instead each one separately.

The fracture resistance data were analyzed by the Kruskal Wallis test with a significance level of 5\%. The failure patterns were evaluated and categorized, and their frequency distribution was recorded.

\section{Results}

The data were normally distributed; however, there was no homoscedasticity of variances. The fracture resistance values ranged between $621.15 \mathrm{~N}(\mathrm{HP})$ and $785.71 \mathrm{~N}(\mathrm{HA})$. However, the Kruskal Wallis test did not reveal differences in the fracture resistance values among the four groups ( $p$ $=0.247$ ). Table 1 presents the descriptive statistics (median and minimum and maximum values) for the groups.

Figure 1 shows the stereomicroscopic images (15x magnification) from cervical portion before and after

Table 1. Median (minimum and maximum values) of fracture resistance (N)

\begin{tabular}{|c|c|c|c|c|}
\hline & $\mathrm{HA}$ & $\mathrm{HP}$ & RA & $\mathrm{RP}$ \\
\hline Median & 826.08 & 633.22 & 733.60 & 609.50 \\
\hline Minimum - Maximum & $427.65-1271.26$ & $167-1147.16$ & $253.01-1642.18$ & $389.49-887.61$ \\
\hline
\end{tabular}

HA: hand preparation and active compaction. HP: hand preparation and passive compaction. RA: rotary preparation and active compaction. RP: rotary preparation and passive compaction. 
preparation. Rotary preparation promoted a smoother and regular canal perimeter. The effect of post space preparation on the cervical portion of the roots was shown in Figure 2. After post space preparation the irregularities had become less intense.

Table 2 presents the failure patterns presented in
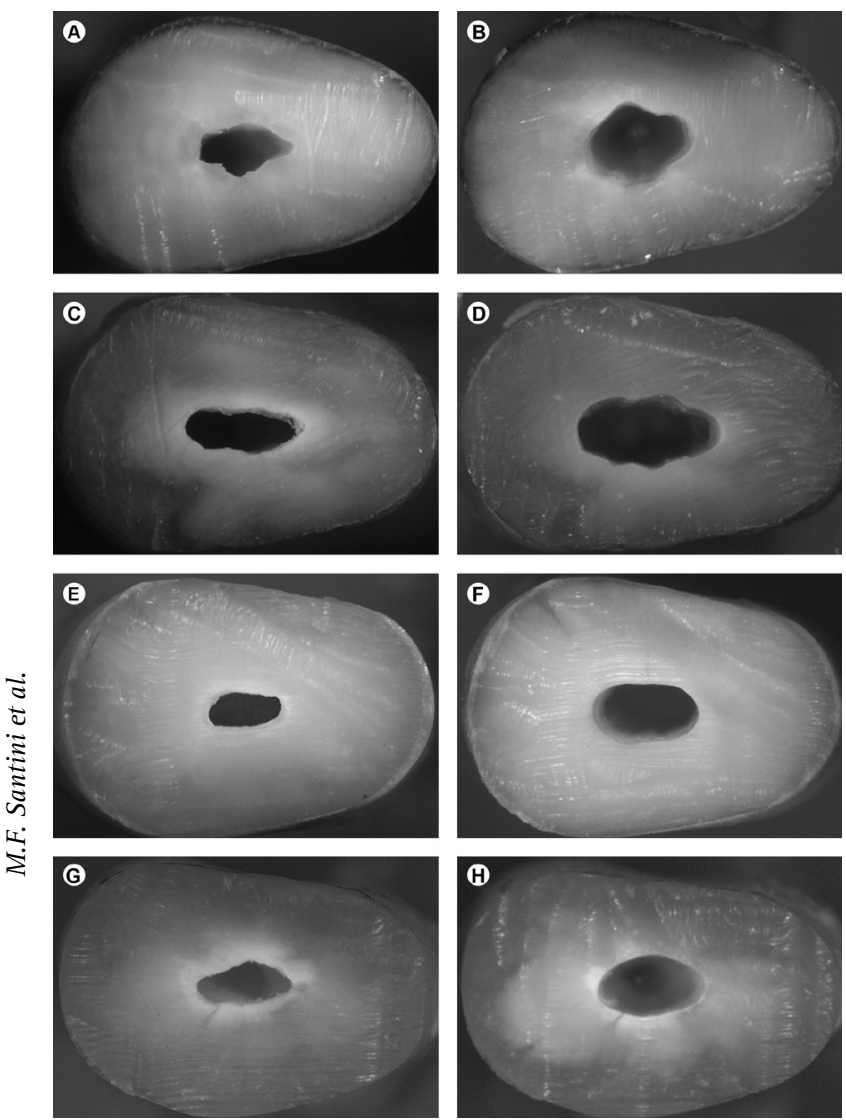

Figure 1. Stereomicroscopy images (15x magnification) of cervical portion of specimens. A and C: before hand preparation. B and D: after hand preparation. $\mathrm{E}$ and $\mathrm{G}$ : before rotary preparation. $\mathrm{F}$ and $\mathrm{H}$, after rotary preparation. each group. Unfavorable failures were predominant in all of the groups. Thirty-eight teeth fractured below the simulated bone level (55.8\% of unfavorable failures). The higher prevalence of unfavorable failures was observed when rotary preparation and active lateral compaction was performed (70.6\%). Among the favorable failure patterns, radicular fracture above the simulated bone level was predominant for all of the groups, except for the hand preparation and active lateral compaction, which presented a prevalence of 5.9\%. The association between hand preparation and active lateral compaction presented predominance of radicular fracture up to the simulated
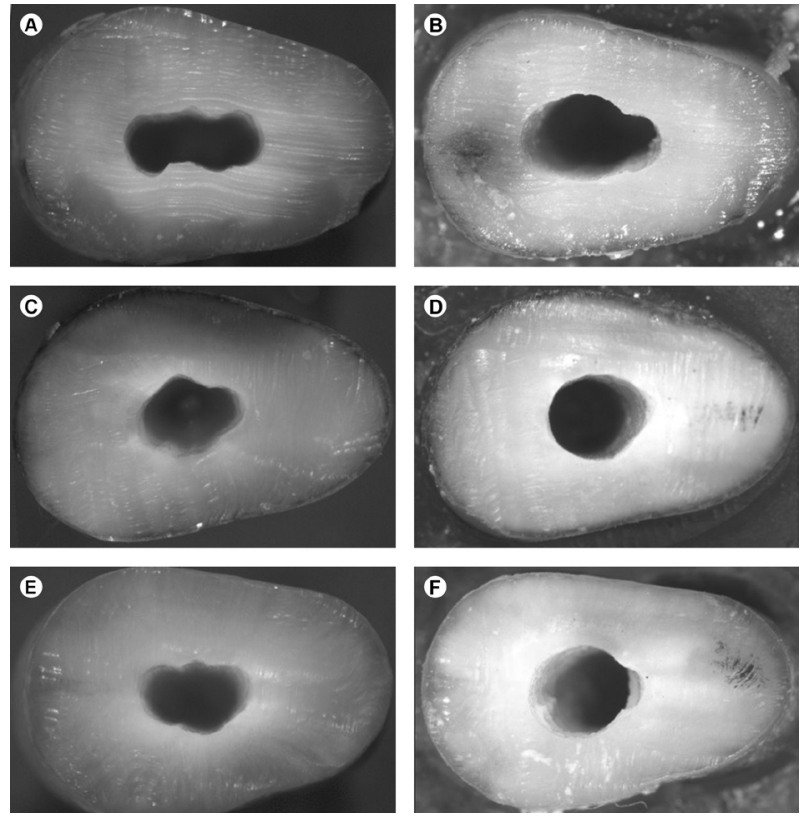

Figure 2. Stereomicroscopy images (15x magnification) of cervical portion of specimens. Effect of post preparation on hand instrumentation group. A, C and E: before post preparation. B, D and F: after post preparation.

Table 2 - Number and percentage of failure patterns in the experimental groups

\begin{tabular}{|c|c|c|c|c|c|}
\hline \multirow[b]{2}{*}{ Groups } & \multicolumn{2}{|c|}{ Favorable } & \multicolumn{2}{|c|}{ Unfavorable } & \multirow{2}{*}{$\begin{array}{c}\text { Total } \\
(100 \%)\end{array}$} \\
\hline & $\begin{array}{l}\text { Displacement of the } \\
\text { crown and/or post }\end{array}$ & $\begin{array}{l}\text { Radicular fracture up to } \\
\text { the simulated bone level }\end{array}$ & $\begin{array}{l}\text { Radicular fracture above } \\
\text { the simulated bone level }\end{array}$ & $\begin{array}{l}\text { Radicular fracture below } \\
\text { the simulated bone level }\end{array}$ & \\
\hline HA & $0(0 \%)$ & $7(41.2 \%)$ & $1(5.9 \%)$ & $9(52.9 \%)$ & 17 \\
\hline $\mathrm{HP}$ & $2(11.8 \%)$ & $2(11.8 \%)$ & $4(23.5 \%)$ & $9(52.9 \%)$ & 17 \\
\hline RA & $0(0 \%)$ & $1(5.9 \%)$ & $4(23.5 \%)$ & $12(70.6 \%)$ & 17 \\
\hline RP & $1(5.9 \%)$ & $2(11.8 \%)$ & $6(35.3 \%)$ & $8(47 \%)$ & 17 \\
\hline Total & $3(4.4 \%)$ & $12(17.6 \%)$ & $15(22.2 \%)$ & 38 (55.8\%) & 68 \\
\hline
\end{tabular}


bone level among the types of favorable failures (41.2\%). Displacement of the crown and/or post was predominant in hand preparation and passive lateral compaction (11.8\%).

Despite the similar fracture resistance values, the combination of rotary preparation and active compaction exhibited a high prevalence of unfavorable fractures. The failures patterns assessed by using transillumination are shown in Figure 3.

\section{Discussion}

The present in vitro study assessed the fracture resistance of extensively damaged teeth restored with fiber post and metallic crown after two root canal preparation techniques (hand and rotary files) and after two filling techniques (active and passive compaction). The results confirmed the null hypotheses because the combination of two preparation and two filling techniques did not influence on the fracture resistance of the teeth.

The restoration of endodontically treated teeth with extensive loss of tooth structure still remains a great challenge for the clinicians. The clinical survival of these teeth depends on several parameters, such as dental type, occlusal load, restorative material used, and remaining tooth structure (16). Additionally, previous studies demonstrated that the endodontic procedures could affect the fracture resistance of teeth $(10,12,17)$.

According to the statistical analysis, canal preparation (hand or rotary) and the filling (passive or active
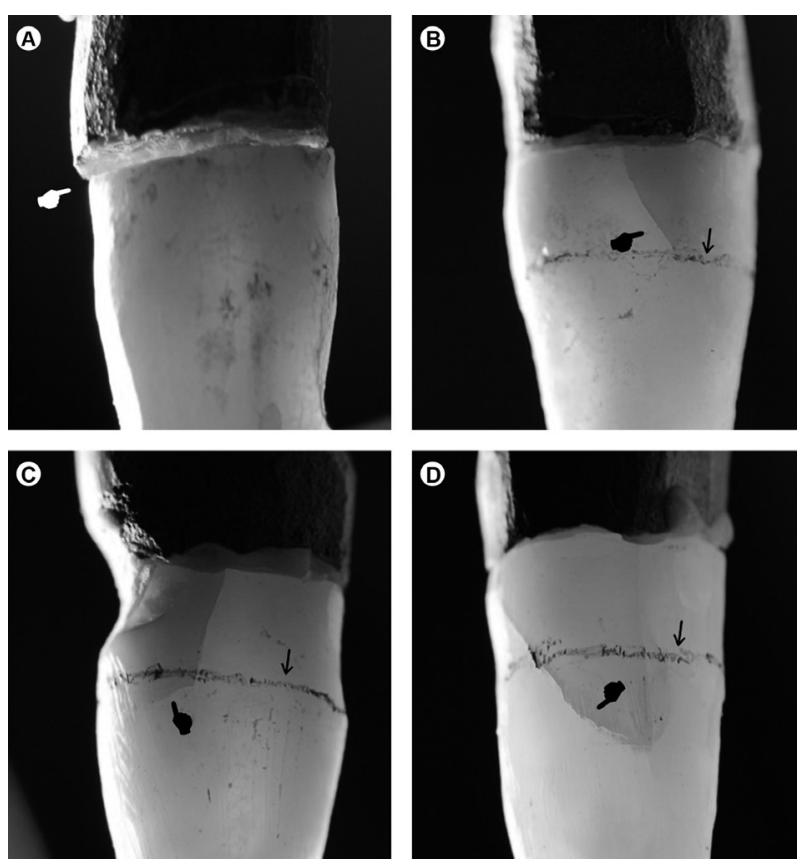

Figure 3. Failure patterns. Favorable: A, displacement of the crown and/ or post. B, radicular fracture up to the simulated bone level. Unfavorable: $\mathrm{C}$ and $\mathrm{D}$, radicular fracture below the simulated bone level $(\rightarrow)$. compaction) techniques did not influence the fracture resistance of the teeth restored with fiber post and metallic crown $(p=0.247)$. All groups presented higher fracture resistance when compared to physiologic chewing loads (290 N at functional normal activity) (18).

Some studies have assessed the effect of different preparations techniques on the appearance of dentinal defects by analyzing the horizontal section of the specimens and examination under a stereomicroscope $(10,12,17)$. Dentin defects or partial cracks are not static, and they may propagate and develop into fractures (19). They also serve as localized sites of increased stress and act in accordance with the theory of stress-concentration (12). Bier et al. (10) observed dentin defects only when rotary files were used for root canal preparation, and hand instrumentation did not induce any defects in the root dentin. The authors attributed these findings to the taper of the preparation performed by the rotary system that had a taper of at least 0.09 . Therefore, more apical dentin was removed when compared with hand files (0.02 taper). Furthermore, more rotations in the canal may contribute to the formation of dentinal defects in rotary preparation group (10).

On the other hand, a finite element analysis (FEA) study demonstrated that hand instrumentation leads to a more irregular preparation than rotary instrumentation and that these irregularities become areas of high stress concentration that might be determinant for crack initiation (20). A regular preparation, as produced by rotary systems, with a minimal induction of dentin defects plays an important role in avoiding the development of root fractures $(10,17,20,21)$.

Different from the researches cited previously, the present study performed endodontic and prosthetic procedures and evaluated their combined effect on fracture resistance of the roots. Although the preparation techniques did not influence the fracture resistance of restored teeth, the images of the cervical region of the roots suggest that rotary preparation provides a more regular root canal perimeter, compared with hand preparation (Fig. 1), and the post space preparation removed the majority of the irregularities that were observed after instrumentation (Fig. 2). Therefore, one possible explanation for the results is that the post space preparation performed by using the post drill regularized the canal walls and eliminated the possible defects caused by the preparation and filling procedures. Therefore, when post space preparation is performed, the possible defects generated by the endodontic procedures may not to have an influence on the fracture resistance of teeth restored with fiber post.

Post preparation requires some dentin removal and the choice of post diameter must be based on the root canal diameter. Previous studies have advocated that dentin 
removal might not be associated with a higher risk of fracture (21-23). The combination of factors such as dentin thickness, degree of curvature, root canal size and shape determines the fracture susceptibility and failure patterns of teeth (23). Preparing a smooth, ovoid-shaped canal reduces the degree of curvature and the susceptibility to fracture. Thus, the elimination of stress concentration at areas such as the buccal and lingual extremities of flattened canals reduces their susceptibility to fracture. Therefore, circular preparations produced by rotary instrumentation and the elimination of high stress concentration at these areas result in uniform tension distribution, thereby compensating for the higher dentin wear.

To create an in vitro condition for material aging, mechanical cycling was carried out to simulate the conditions of humidity and temperature in the oral cavity. Mechanical cycling consists of application of small intermittent loads such that one application does not cause apparent damage to the tooth structure (24). The application of intermittent loads may contribute to the expansion of small defects that are created during endodontic and prosthetic treatment (24). Mechanical cycling alone was not capable of inducing a VRF; however, when prepared teeth filled with active filling techniques were cycled, VRFs were observed in 13.3\% (Lateral compaction) and 33.3\% (Tagger's hybrid technique) of the cases (17). In addition, root fractures may result from pre-existing defects, and therefore, they should not be considered as an instantaneous phenomenon. These findings show the importance of aging the specimens before performing the resistance fracture tests.

The periodontal ligament is responsible for distributing the loads over the tooth; therefore, the ligament must be simulated when mechanical cycling or fracture resistance tests are carried out. Elastomeric materials are used for this purpose, and they are responsible for force distribution around the tooth and effective stress distribution when lateral compaction, mechanical cycling or fracture resistance test are performed $(12,25)$. The use of elastomeric materials simulates biological conditions and allows for the removal of the root from the simulated alveolus and, consequently, the observation of fractures that occur not only in the cervical third but also in the middle and apical third of the root.

As the current study is an in vitro study, it has some limitations since the methodology chosen cannot perfectly reproduce clinical conditions. One of the difficulties was the inclusion of a control group. Maxillary canines were decoronated to create the worst-case scenario for the remaining tooth structure. The primary goal of this study was to evaluate fracture strength of extensively damaged teeth with prosthetic needs. Therefore, the inclusion of a control group, with sound teeth, did not seem not reasonable. The combination of hand preparation and active compaction assumed the role of a control group because they are a largely used worldwide for the preparation and filling of the canals, respectively. Other limitation was the use of monotonic compression test to assess the fracture resistance of the specimens. In these tests, a single and increasing load is applied until some failure occurs and, normally, irreparable root fractures are the main failure pattern, as was observed in this study. Therefore, to improve the understanding of the biomechanical behavior of the restorative complex, studies should also include dynamic tests, such as mechanical cycling.

Within the limitations of this study, it can be concluded that the root canal preparation and the filling techniques had no influence on the fracture resistance of extensively damaged teeth restored with fiber posts and metallic crowns. All groups exhibited higher fracture resistance values than those usually found in patients with normal occlusion. The major failure pattern was unfavorable, described as radicular fracture below the simulated bone level (55.8\%).

\section{Resumo}

0 objetivo deste estudo foi avaliar a resistência à fratura de dentes amplamente destruídos após duas técnicas de preparo (limas manual e rotatória) e após duas técnicas obturadoras (compactação ativa e passiva). Sessenta e oito raízes de caninos superiores com diâmetro apical igual a uma lima K \#25 foram embutidas em resina acrílica e o ligamento periodontal foi simulado utilizando um material de moldagem à base de poliéter. As raizes foram distribuidas aleatoriamente em quatro grupos $(n=17)$ : preparo manual e compactação ativa (MA), preparo manual e compactação passiva (MP), preparo rotatório e compactação ativa (RA) e preparo rotatório e compactação passiva (RP). Todas as raizes foram restauradas com pino de fibra de vidro e coroa metálica. Os espécimes foram ciclados mecanicamente $\left(500.000\right.$ ciclos, $\left.45^{\circ}, 37^{\circ} \mathrm{C}, 133 \mathrm{~N}, 2 \mathrm{~Hz}\right)$ e depois submetidos ao teste de resistência à fratura. Um único examinador cego analisou a superfície externa das raizes e classificou o padrão de falha em favorável ou desfavorável. Os valores de resistência à fratura variaram entre $621,15 \mathrm{~N}$ (MP) e 785,71 N (MA). Entretanto, o teste de Kruskal-Wallis não revelou diferença nos valores de resistência à fratura entre os quatro grupos $(p=0,247)$. Diante das condições testadas, as técnicas de preparo e de obturação do canal radicular não influenciam na resistência à fratura de dentes amplamente destruídos restaurados com pino de fibra de vidro e coroa metálica.

\section{Acknowledgements}

This study was supported by grants from the Brazilian funding agency CNPq (grants\#470594/2011-0). The authors are grateful to WILCOS and FGM for partially supplying the products used in the study.

\section{References}

1. Touré B, Faye B, Kane AW, Lo CM, Niang B, Boucher Y. Analysis of reasons for extraction of endodontically treated teeth: a prospective study. J Endod 2011;37:1512-1515.

2. Tsesis I, Rosen E, Tamse A, Taschieri S, Kfir A. Diagnosis of vertical 
root fractures in endodontically treated teeth based on clinical and radiographic indices: A systematic review. J Endod 2010;36:1455-1458.

3. Berman LH, Kuttler S. Fracture necrosis: diagnosis, prognosis assessment, and treatment recommendations. J Endod 2010;36:442446.

4. Langer B, Stein SD, Wagenberg B. An evaluation of root resections: a ten year study. J Periodontol 1981;52:719-722.

5. Fuss Z, Lustig J, Tamse A. Prevalence of vertical root fractures in extracted endodontically treated teeth. Int Endod J 1999;32:283-286.

6. Tang $W, W u Y$, Smales RJ. Identifying and reducing risks for potential fractures in endodontically treated teeth. J Endod 2010;36:609-617.

7. Azevedo RA, Silva-Sousa YT, Souza-Gabriel AE, Messias DC, Alfredo E, Silva RG. Fracture resistance of teeth subjected to internal bleaching and restored with different procedures. Braz Dent J 2011;22:117-121.

8. Silva GR, Santos-Filho PC, Simamoto-Júnior PC, Martins LR, Mota AS, Soares $\mathrm{CJ}$. Effect of post type and restorative techniques on the strain and fracture resistance of flared incisor roots. Braz Dent J 2011;22:230237.

9. Rippe MP, Santini MF, Bier CA, Borges AL, Valandro LF. Root canal filling: fracture strength of fiber-reinforced composite-restored roots and finite element analysis. Braz Dent J;24:619-625.

10. Bier CAS, Shemesh H, Tanomaru-Filho F, Wesselink PR, Wu M-K. The ability of different nickel-titanium rotary instruments to induce dentinal damage during canal preparation. J Endod 2009;35:236-238.

11. Saw LH, Messer HH. Root strains associated with different obturation techniques. J Endod 1995;21:314-320.

12. Lertchirakarn $\mathrm{V}$, Palamara JE, Messer $\mathrm{HH}$. Load and strain during lateral condensation and vertical root fracture. J Endod 1999;25:99-104.

13. Shemesh H, Bier CAS, Wu M-K, Tanomaru-Filho M, Wesselink PR. The effects of canal preparation and filling on the incidence of dentinal defects. Int Endod J 2009;42:208-213.

14. Tjan AH, Whang SB. Resistance to root fracture of dowel channels with various thicknesses of buccal dentin walls. J Prosthet Dent 1985;53:496-500.

15. Giovani AR, Vansan LP, de Sousa Neto MD, Paulino SM. In vitro fracture resistance of glass-fiber and cast metal posts with different lengths. $J$ Prosthet Dent 2009;101:183-188.

16. Assif D, Gorfil C. Biomechanical considerations in restoring endodontically treated teeth. J Prosthet Dent 1994;71:565-567.

17. Barreto MS, Moraes RA, Rosa RA, Moreira CH, Só MV, Bier CA. Vertical root fractures and dentin defects: effects of root canal preparation, filling, and mechanical cycling. J Endod 2012;38:1135-9.

18. Ferrario VF, Sforza C, Serrao G, Dellavia C, Tartaglia GM. Single tooth bite forces in healthy young adults. J Oral Rehabil 2004;31:18-22.

19. Wilcox LR, Roskelley $C$, Sutton T. The relationship of root canal enlargement to finger-spreader induced vertical root fracture. J Endod 1997;23:533-534.

20. Sathorn C, Palamara JEA, Messer HH.A comparison of the effects of two canal preparation techniques on root fracture susceptibility and fracture pattern. J Endod 2005;31:283-287.

21. Lertchirakarn $\mathrm{V}$, Palamara JE, Messer $\mathrm{HH}$. Finite element analysis and strain-gauge studies of vertical root fracture. J Endod 2003;29:529534.

22. Lam PP, Palamara JE, Messer HH. Fracture strength of tooth roots following canal preparation by hand and rotary instrumentation. J Endod 2005;31:529-532.

23. Sathorn C, Palamara JEA, Palamara D, Messer HH. Effect of root canal size and external root surface morphology on fracture susceptibility and pattern: a finite element analysis. J Endod 2005;31:288-292.

24. Wiskott HWA, Nicholls JL, Belser UC. Stress fatigue: basic principles and prosthodontic implications. Int J Prosthodont 1995;8:105-116.

25. Soros C, Zinelis S, Lambrianidis T, Palaghias G. Spreader load required for vertical root fracture during lateral compaction ex vivo: evaluation of periodontal simulation and fracture load information. Oral Surg Oral Med Oral Pathol Oral Radiol Endod 2008;106:e64-e70.

Received January 3, 2014 Accepted February 25, 2014 